\title{
Sloshing Damping in a Swaying Rectangular Tank Using a Porous Bulkhead
}

\author{
Il-Hyoung Cho®* \\ *Department of Ocean System Engineering, Jeju National University, Jeju, Korea \\ 투과성 격벽을 이용한 수평 운동하는 사각형 탱크내의 슬로싱 감쇠 \\ 조일형(1* \\ "제주대학교 해양시스템공학과
}

KEY WORDS: Porous bulkhead 투과성 격벽, Energy dissipation 에너지 손실, Porosity coefficient 공극률 계수, 모형 실험 Model test, Sloshing 슬로싱, Resonant frequency 공진 주파수

\begin{abstract}
The performance of a porous swash bulkhead for the reduction of the resonant liquid motion in a swaying rectangular tank was investigated based on the assumption of linear potential theory. The Galerkin method (Porter and Evans, 1995) was used to solve the potential flow model by adding a viscous frictional damping term to the free-surface condition. By comparing the experimental results and the analytical solutions, we verified that the frictional damping coefficient was 0.4. Darcy's law was used to consider the energy dissipation at a porous bulkhead. The tool that was developed with a built-in frictional damping coefficient of 0.4 was confirmed by small-scale experiments. Using this tool, the free-surface elevation, hydrodynamic force (added mass, damping coefficient) on a wall, and the horizontal load on a bulkhead were assessed for various combinations of porosity and submergence depth. It was found that the vertical porous bulkhead can suppress sloshing motions significantly when properly designed and by selecting the appropriate porosity $(\approx 0.1)$ and submergence depth.
\end{abstract}

\section{1. 서 론}

선박내에 탑재된 탱크에 채워진 액체화물은 탱크의 형상과 액체화물이 채워진 깊이에 따라 변하는 고유주기를 갖는다. 다 양한 주기를 갖는 불규칙 파랑중에서 운동하는 선박의 운동주 기와 탱크내 액체화물의 고유주기가 일치하면 공진현상이 발생 하여 탱크내의 액체화물은 격렬한 운동을 한다. 이를 슬로싱 (Sloshing) 현상이라 부른다. 탱크내의 액체화물은 탱크 내부 구 조물에 강한 충격력을 가하게 되고 이는 구조물의 안정성과 선 박의 안전한 항해에 악 영향을 끼친다. 또한 높아진 탱크내의 수위는 쇄파(Breaking wave)로 이어져 액체와 공기가 혼합되어 기포가 생기고 기포가 터지면서 충격력이 발생한다. 탱크내의 슬로싱 현상을 규명하기 위한 다양한 이론해와 수치해 그리고 모형실험에 관한 연구가 진행되어 왔고, 슬로싱 현상을 줄이기 위한 다양한 장치 개발도 함께 병행되었다.

공진으로 크게 증폭된 탱크내의 수면 변동을 줄이거나 탱크 내 액체화물의 고유주기를 슬로싱의 영향이 심각하지 않은 주 기 대역으로 변경하는 목적으로 탱크 내부에 제수 격벽(Swash bulkhead)을 설치한다. 격벽은 불투과성 격벽과 일정한 공극률
(Porosity)을 갖는 투과성 격벽(Warnitchai and Pinkaew, 1998)으 로 나눌 수 있다. 또한 격벽의 설치 방법에 따라 주 흐름 방향과 직각이 되게 설치하는 직립형(Fediw et al., 1995; Cho and Kim, 2016)과 파랑에너지가 밀집된 수면 가까이 수면과 평행하게 설 치하는 수평형(Cho et al., 2017)으로 구분된다. 원리는 격벽 끝 단에서 일어나는 박리(Separation)로 와류(Eddy)를 발생시켜 탱 크내의 에너지를 소멸시킨다. 투과성 격벽인 경우, 흐름이 투과 성 격벽을 통과할 때 갑작스런 형상의 변화로 인해 구멍을 통 하여 소용돌이가 형성되고 이로 인한 흐름 저항(Flow resistance) 으로 에너지 손실이 더해진다. 따라서 투과성 격벽을 통과하면 서 생기는 에너지 손실효과는 격벽의 공극률과 설치 방법, 그리 고 잠긴 깊이와 밀접한 관련이 있다.

Evans(1970)는 선형포텐셜 이론을 기반으로 하여 수면 아래 잠 긴 불투과성 직립 판에 작용하는 1 차 및 2 차 파랑 하중과 모멘트 를 구하였다. Losada et al.(1992)와 Abul-Azm(1993)은 불투과성 판이 서로 다른 배치 형상을 갖고 수중에 수직으로 놓여 있을 때 의 경사파의 회절 문제를 고유함수전개법(Matched eigenfunction expansion method)을 사용하여 풀었다. Porter and Evans(1995)는 불투과성 판에 의한 경사파의 회절 문제를 Galerkin 방법을 사용

Received 17 July 2018, revised 10 August 2018, accepted 14 August 2018

Corresponding author Il-Hyoung Cho: +82-64-754-3482, cho0904@jejunu.ac.kr ORCID: http://orcid.org/0000-0002-4005-2724

(c) 2018, The Korean Society of Ocean Engineers

This is an open access article distributed under the terms of the creative commons attribution non-commercial license (http://creativecommons.org/licenses/by-nc/3.0) which permits unrestricted non-commercial use, distribution, and reproduction in any medium, provided the original work is properly cited. 
하여 풀어 보다 높은 정확도를 갖는 반사율과 투과율을 얻었다. Galerkin 방법의 장점은 판 끝단 근처에서의 유속의 특이 거동 (Singular behavior)을 정확하게 모델링 할 수 있다는 점이다. 따라 서 수중에 놓여 있는 얇은 판의 회절 문제에서 고유함수전개법보 다 수렴성이 우수하여 짧은 계산 시간에도 불구하고 매우 정확한 결과를 준다.

투과성 판을 통한 에너지 손실의 정확성은 투과성 판에 적용 하는 에너지 손실모델에 따라 달라진다. 투과성 판 전후의 압력 차와 투과성 판에서의 속도가 선형적으로 비례하는 에너지 손 실모델을 Darcy 법칙이라 부른다. 이때 비례상수는 일반적으로 복소수 값을 가지며 실수부를 차단계수(Blockage coefficient), 허 수부를 에너지 손실과 밀접한 관련된 항력계수(Drag coefficient) 라 부른다. Crowley and Porter(2012)는 투과성 판 전후의 압력차 는 속도 제곱에 비례하는 비선형 손실모델을 제안하였고, 등가 선형화 과정을 통한 선형 문제와 비선형 문제로 나누어 풀어 둘 사이의 정량적인 값 차이를 비교하였다.

투과성 판을 탱크내 슬로싱 문제에 적용한 대표적인 논문들 은 다음과 같다. Faltinsen et al.(2011)은 사각형 탱크 중앙에 투 과성 격벽을 설치하였을 때의 슬로싱 문제를 다루었다. 에너지 손실모델로 압력차가 유속 제곱에 비례하는 비선형 모델을 사 용하였다. Crowley and Porter(2012)는 2차원 사각형 탱크내에 놓 인 다수의 투과성 직립 격벽을 모델링하기 위하여 Darcy 법칙

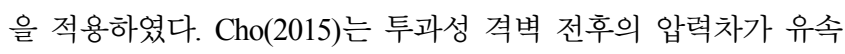
의 제곱에 비례한다고 가정한 비선형 에너지 손실모델을 사각 형 탱크내의 중앙에 설치된 투과성 격벽에 적용하였다. Cho and $\operatorname{Kim}(2016)$ 은 $\mathrm{Cho}(2015)$ 의 연구를 확장하여 투과성 이중 격벽이 탱크내에 놓여 있을 때의 해석해를 구하고, 모형실험결과와 비 교하였다. Cho et al.(2017)는 Darcy 법칙을 적용하여 사각형 탱 크내에 수평형 투과성 격벽이 설치되었을 때 슬로싱 감쇠 효과 를 고유함수전개법을 사용하여 해석하였다. 해석결과는 BEM (Boundary element method)을 이용한 수치해석결과와 모형실험 결과와 비교하였다.

본 연구에서는 사각형 탱크내의 중앙에 설치된 투과성 격벽 을 통하여 발생하는 에너지 손실효과를 Darcy 법칙을 적용한 선형모델로 구현하여 투과성 격벽에 의한 슬로싱 감쇠 효과를 살펴보았다. 또한 탱크의 벽과 바닥에서의 점성 마찰에 의한 에 너지 손실을 자유표면 경계조건식내에 인위적인 마찰 감쇠계수 를 추가하여 나타내었다. 이때 감쇠계수는 격벽이 없는 순수한 탱크의 모형실험결과와 정량적인 비교를 통하여 구하였다. 마 찰 감쇠계수를 장착한 설계 도구를 이용하여 계산된 해석결과 는 모형실험을 통하여 측정된 수위와 압력 데이터와 정량적으 로 잘 일치하였다. 탱크의 주파수와 함께 투과성 격벽의 공극 률, 잠긴 깊이를 변화시켜가면서 탱크내의 수위 변위, 탱크 벽 면에 작용하는 동유체력(부가질량, 감쇠계수), 투과성 격벽에 작 용하는 수평 하중을 구하고, 그 특성들을 분석하였다.

\section{2. 문제의 정식화}

폭 $2 a$ 인 사각형 탱크의 중앙에 잠긴 깊이 $d$ 인 투과성 격벽이 수직으로 놓여 있다(Fig. 1 참조). 탱크내의 유체는 비점성, 비압

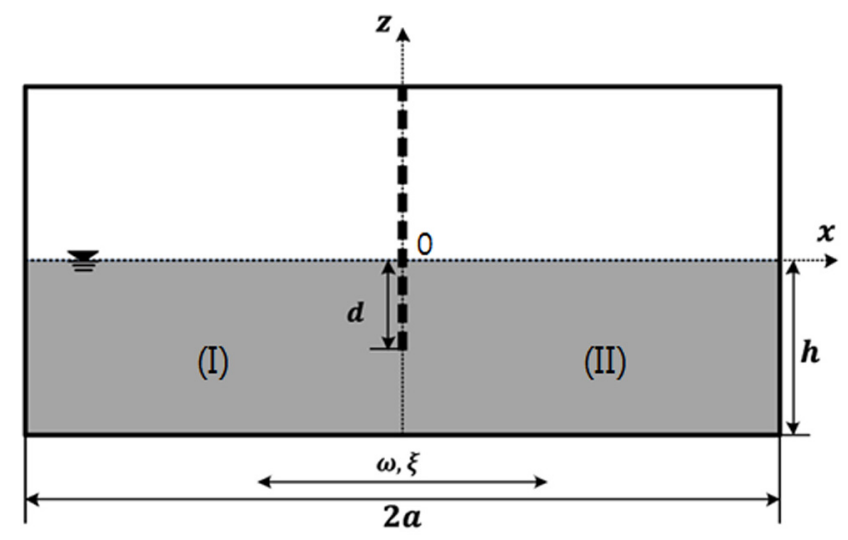

Fig. 1 Definition sketch of a swaying rectangular tank with a centrally placed porous bulkhead.

축성이며, 비회전성 유동을 가정한다. 깊이 $h$ 만큼 액체화물을 채운 탱크가 주파수 $\omega$ 를 가지고 수평 방향으로 조화운동을 할 때, 탱크내의 수위와 유속을 선형포텐셜 이론을 사용하여 해석 하였다. 속도포텐셜 함수를 도입하여 시간과 공간의 함수로 분 리하여 쓰면 $\Phi(x, z, t)=\operatorname{Re}\left\{u_{T} \phi(x, z) e^{-i \omega t}\right\}$ 이다. 여기서 $u_{T}(=-i \omega \xi)$ 는 탱크의 수평 운동 속도를 뜻하며, $\xi$ 은 수평 운동 변위를 나 타낸다. 수평 운동 모드는 $z$ 축에 대해 비대칭 운동 모드이므로 $\phi(x, z)=-\phi(-x, z)$ 가 성립한다. 따라서 탱크내의 전체 유체영역 을 다루지 않고 $x \leq 0$ 영역만을 다루고 대칭 관계식을 이용하 여 $x>0$ 로 확장한다. 속도포텐셜 $(\phi)$ 에 대한 2 차원 경계치문제 를 구성하면 다음과 같다.

$$
\begin{aligned}
& \nabla^{2} \phi=0 \\
& \frac{\partial \phi}{\partial z}-\frac{\left(\omega^{2}+i \omega \varepsilon\right)}{g} \phi=0, \quad \text { on } z=0 \\
& \frac{\partial \phi}{\partial z}=0, \quad \text { on } z=-h,-a \leq x \leq 0 \\
& \frac{\partial \phi}{\partial x}=1, \quad \text { on } x=-a,-h \leq z \leq 0
\end{aligned}
$$

탱크의 벽과 바닥에서의 점성 마찰에 의한 감쇠효과를 고려 하기 위하여 자유표면경계조건식 (2)안에 Rayleigh 감쇠 항 (Damping term)을 포함시켰다. $\varepsilon$ 는 점성 마찰에 의한 에너지 손 실을 나타내는 감쇠계수이다. 이 값은 3 장에서 다룰 모형실험결 과와 비교를 통하여 얻는다.

탱크의 수평 운동에 의한 탱크내의 유동을 나타내는 속도포 텐셜은 식 (1)-(4)를 만족하며 다음과 같이 쓸 수 있다.

$$
\phi(x, z)=\sum_{n=0}^{\infty} \frac{1}{k_{n}}\left[A_{n} e^{k_{n} x}-B_{n} e^{-k_{n}(x+a)}\right] f_{n}(z)
$$

식 (5)에서 고유함수 $\left(f_{n}\right)$ 는 아래 주어진 Strüm-Liouville형 고 유치 문제(Eigenvalue problem)를 만족한다. 


$$
\left\{\begin{array}{l}
\frac{d^{2} \tilde{f}}{d z^{2}}+\kappa^{2} \tilde{f}=0, \quad z<0 \\
\frac{\partial \tilde{f}}{\partial z}-\frac{\left(\omega^{2}+i \omega \varepsilon\right)}{g} \tilde{f}=0, \quad \text { on } z=0 \\
\frac{d \tilde{f}}{d z}=0, \quad \text { on } z=-h
\end{array}\right.
$$

식 (6)을 만족하는 고유함수는 $\tilde{f}=\cos \kappa(z+h) / \cos \kappa h$ 이며, 이 함수를 식 (6)의 두 번째 식에 대입하면, 고유값 $\kappa$ 는 아래 주어 진 분산식을 만족한다.

$$
\kappa \tan \kappa h=-\frac{\left(\omega^{2}+i \omega \varepsilon\right)}{g}
$$

식 (7)에 주어진 분산식의 해는 무한개이다. 따라서 고유값과 고유함수를 $\kappa=k_{n}, \tilde{f}(z)=f_{n}(z), n=0,1,2, \ldots$ 로 쓸 수 있다. 이 때 고유함수는 아래 직교성(Orthogonality)을 만족한다.

$$
\begin{gathered}
\int_{-h}^{0} f_{m}(z) f_{n}(z) d z=N_{n} \delta_{m n} \\
N_{n}=\frac{1}{\cos ^{2} k_{n} h}\left(\frac{h}{2}+\frac{\sin 2 k_{n} h}{4 k_{n}}\right)
\end{gathered}
$$

여기서 $\delta_{m n}$ 는 $m=n$ 일 때 1 이고, $m \neq n$ 일 때 0 의 값을 갖는 Kronecker-Delta함수이다.

탱크 벽 $(x=-a)$ 에서의 경계조건식 (4)로부터 아래와 같은 관 계식을 유도할 수 있다.

$$
B_{n}=-\gamma_{n}-A_{n} e^{-k_{n} a}
$$

여기서 $\gamma_{n}$ 는 1 를 고유함수의 전개식 $\left(\sum_{n=0}^{\infty} \gamma_{n} f_{n}(z)\right)$ 으로 표현하였 을 때의 계수이며, 고유함수의 직교성을 이용하여 아래와 같이 구할 수 있다.

$$
\gamma_{n}=\frac{1}{N_{n}} \int_{-h}^{0} f_{n}(z) d z
$$

투과성 격벽이 놓인 $x=0$ 에서의 경계조건식을 적용하기에 앞 서 격벽 $(x=0)$ 에서의 수평 방향 유체 속도를 $U(z)$ 라 놓고 이를 고유함수 $f_{n}(z)$ 의 전개식으로 표현하면 다음과 같다.

$$
U(z)=\frac{\partial \phi}{\partial x}(0, z)=\sum_{n=0}^{\infty} U_{n} f_{n}(z)
$$

식 (5)를 식 (11)에 대입하고 식 (9)을 이용하면 미지수 $A_{n}, B_{n}$ 을 식 (11)의 전개식의 계수 $U_{n}$ 로 나타낼 수 있다.

$$
A_{n}=\frac{U_{n}-\gamma_{n} e^{-k_{n} a}}{1-e^{-2 k_{n} a}}, B_{n}=\frac{\gamma_{n}-U_{n} e^{-k_{n} a}}{1-e^{-2 k_{n} a}}
$$

식 (12)를 식 (5)에 대입한 뒤 정리하면 속도포텐셜을 아래와 같이 쓸 수 있다.

$$
\phi=\sum_{n=0}^{\infty} \frac{f_{n}(z)}{k_{n} \sinh k_{n} a}\left[U_{n} \cosh k_{n}(x+a)-\gamma_{n} \cosh k_{n} x\right]
$$

투과성 격벽에서의 경계조건식으로 연속방정식 (14)와 함께 식 (15)에 주어진 Darcy법칙을 사용하였다.

$$
\begin{aligned}
& {\left[\frac{\partial \phi}{\partial x}\right]_{x=0^{-}}^{x=0^{+}}=0 \text { on }-h \leq z \leq 0} \\
& \phi\left(0^{-}, z\right)-\phi\left(0^{+}, z\right)= \begin{cases}\frac{1}{i \sigma} U_{r}(z)=\frac{1}{i \sigma}[U(z)-1], & -d \leq z \leq 0 \\
0, & -h \leq z \leq-d\end{cases}
\end{aligned}
$$

여기서 $\sigma$ 는 공극률 계수(Porosity coefficient)로서 투과성 격벽의 공극률과 국부형상에 밀접한 관련이 있다(Chwang and Wu, 1994, Cho and Kim, 2008). 실제 계산에서는 무차원화시킨 공극률 계수 $b\left(=\frac{2 \pi \sigma}{k}\right)$ 를 사용하였다. $b \rightarrow 0$ 는 불투과성 판을 의미하며, $b \rightarrow \infty$ 는 유체 흐름에 전혀 영향을 주지 않는 가상의 판이 놓여 있는 경우이다.

Cho and $\operatorname{Kim}(2008)$ 은 공극률을 바꿔가면서 모형실험결과와 해석결과를 비교하여 공극률 계수와 판의 공극률 사이에는 $b=57.63 P-0.9717$ 인 선형 관계가 유지됨을 밝혔다. 3 장에서 소 개할 모형실험에서 투과성 격벽으로 Cho and $\mathrm{Kim}(2008)$ 가 사용 한 동일한 투과성 판을 사용하였다. 따라서 공극률에 대응하는 공극률 계수를 얻기 위하여 위의 선형관계식을 사용하였다. $U_{r}$ 는 탱크와 유체의 상대 수평 속도를 나타낸다.

Porter and Evans(1995)의 Galerkin 방법에 따라 투과성 격벽의 유무에 따라 격벽 전후의 속도포텐셜의 차이를 아래와 같이 Chebychev의 다항식을 포함한 기저함수(Basis function)로 전개 시키면 다음과 같다.

$$
\phi\left(0^{-}, z\right)-\phi\left(0^{+}, z\right)= \begin{cases}\sum_{p=0}^{\infty} a_{p} \chi_{p}(z), & -d \leq z \leq 0 \\ 0, & -h \leq z \leq-d\end{cases}
$$

식 (16)의 $a_{p}$ 는 전개식의 계수이며, 기저함수 $\chi_{p}(z)$ 는 아래와 같이 정의된다.

$$
\begin{aligned}
& \hat{\chi}_{p}(z)=\chi_{p}(z)-\frac{\left(\omega^{2}+i \omega \mu\right)}{g} \int_{-d}^{z} \chi_{p}(\tau) d \tau \\
& \text { where } \hat{\chi}_{p}(z)=\frac{2(-1)^{p} \sqrt{d^{2}-z^{2}}}{\pi(2 p+1) d h} T_{2 p}\left(-\frac{z}{d}\right)
\end{aligned}
$$

여기서 $T_{n}(x)$ 는 $n$ 차 Chebychev의 다항식으로 $T_{n}(x)=\frac{\sin (n+1) \theta}{\sin \theta}$, $x=\cos \theta$ 이다. $\chi_{p}(z)$ 은 자유표면경계조건식을 만족하며 진자판 끝단 
$(z=-d)$ 에서의 제곱근 $(\sqrt{ })$ 의 특이성을 나타내고 있다. 식 (13)을 식 (16)에 대입하고, 양변에 $f_{m}(z), m=0,1,2, \ldots$ 를 곱한 뒤, $z$ 에 대하여 적분하면 아래의 관계식을 얻을 수 있다.

$$
\frac{U_{m}}{k_{m} \tanh k_{m} a}-\frac{\gamma_{m}}{k_{m} \sinh k_{m} a}=\frac{1}{2 N_{m}} \sum_{p=0}^{\infty} a_{p} F_{p m}
$$

여기서

$$
\begin{aligned}
F_{p m} & =\int_{-d}^{0} \chi_{p}(z) f_{m}(z) d z=\int_{-d}^{0} \hat{\chi}_{p}(z) \cos k_{m} z d z \\
& =\frac{J_{2 p+1}\left(k_{m} d\right)}{k_{m} h}, \quad m=0,1,2, . .
\end{aligned}
$$

식 (19)에서 $J_{2 p+1}$ 는 $(2 p+1)$ 차 Bessel함수를 나타낸다. 식 (18)을 이용하여 식 (13)을 다시 쓰면 다음과 같다.

$$
\phi=\sum_{n=0}^{\infty}\left\{\begin{array}{l}
\frac{1}{\left(2 N_{n}\right)} \sum_{p=0}^{\infty} a_{p} F_{p n} \frac{\cosh k_{n}(x+a)}{\cosh k_{n} a} \\
+\frac{\gamma_{n}}{k_{n} \sinh k_{n} a}\left(\frac{\cosh k_{n}(x+a)}{\cosh k_{n} a}-\cosh k_{n} x\right)
\end{array}\right\} f_{n}(z)
$$

식 (20)을 식 (15)에 대입한 후 양변에 $p_{m}(z),(m=0,1,2, \ldots)$ 을 곱하고, $z$ 에 대하여 적분하면 아래와 같은 대수방정식을 유도 할 수 있다. 이때 기저함수의 개수 $(p, m=0,1,2, \ldots, M)$ 와 고유함수 의 개수 $(n=0,1,2, \ldots, N)$ 는 유한개를 취한다.

$$
\sum_{p=0}^{M} a_{p}\left\{\sum_{n=0}^{N} \frac{\left(2 i \sigma-k_{n} \tanh k_{n} a\right)}{2 N_{n}} F_{p n} F_{m m}\right\}=\sum_{n=0}^{N} \gamma_{n}\left(\frac{1}{\cosh k_{n} a}-1\right) F_{m n}
$$

식 (21)에 주어진 대수방정식을 풀어 미지수 $a_{p}(p=0,1,2, ., M)$ 을 구한 뒤, 식 (20)에 대입하면 탱크의 수평 운동에 의한 탱크 내의 유동에 대한 완전한 해를 구할 수 있다.

식 (18)에서 투과성 격벽이 없을 때 $\left(a_{p}=0\right), U_{m}=\gamma_{m} / \cosh k_{m} a$ 이다. 이를 식 (13)에 대입하면 내부가 없는 순수한 탱크가 수평 운동을 할 때의 속도포텐셜을 구할 수 있다.

$$
\phi(x, z)=\sum_{n=0}^{N} \frac{\gamma_{n} \sinh k_{n} x}{k_{n} \cosh k_{n} a} f_{n}(z)
$$

탱크의 수평 운동에 의한 탱크 벽에 작용하는 $x$ 방향의 동유 체력 $\left(F=R e\left\{f e^{-i \omega t}\right\}\right)$ 은 탱크 벽에서의 압력을 적분하여 구할 수 있다.

$$
f=-2 \rho \omega^{2} \xi\left\{\int_{-h}^{0} \phi(-a, z) d z\right\}
$$

동유체력 $f$ 를 실수부와 허수부로 나누면 다음과 같다.

$$
f=\left(\omega^{2} \mu+i \omega \nu\right) \xi
$$

여기서 $\mu$ 는 부가질량이며, $\nu$ 는 감쇠계수이다.

같은 방법으로 탱크의 수평 운동에 의한 투과성 격벽에 작용 하는 하중 $\left(F_{b}=\operatorname{Re}\left\{f_{b} e^{-i \omega t}\right\}\right)$ 은 다음과 같다.

$$
f_{b}=\rho \omega^{2} \xi \int_{-d}^{0}\left[\phi\left(0^{-}, z\right)-\phi\left(0^{+}, z\right)\right] d z
$$

탱크내의 수면 변위와 탱크 벽에서의 압력은 다음과 같이 구 할 수 있다.

$$
\eta(x)=\frac{\omega^{2} \xi}{g} \phi(x, 0), p(z)=\rho \omega^{2} \xi \phi(-a, z)
$$

\section{3. 모형 실험}

모형실험에 사용한 사각형 탱크의 제원은 길이 $50 \mathrm{~cm}$, 높이 $50 \mathrm{~cm}$, 폭 $12 \mathrm{~cm}$ 이다. 탱크내 액체의 깊이는 $10 \mathrm{~cm}$ 이다. 탱크내 유 동의 변화를 밖에서 볼 수 있도록 투명한 아크릴로 제작하였다. 탱크의 수평 운동 변위는 $3 \mathrm{~mm}$ 로 고정하였고, 운동 주기의 범위 를 $0.25 \mathrm{~s} \leq T \leq 1.4 \mathrm{~s}$ 로 하였다. 투과성 격벽은 두께 $2 \mathrm{~mm}$ 인 얇은 철판 위에 직경 $3 \mathrm{~mm}$ 인 구멍이 일정한 간격을 갖고 균일하게 배 열된 형태이다. 배열 간격을 조절하여 서로 다른 공극률 $(0.0567$, $0.1275,0.3265)$ 을 갖는 투과성 격벽을 만들어 모형실험을 수행하 였다.

탱크내 실시간으로 변하는 수위 변화를 얻기 위하여 촬영된 실험 동영상을 후처리하여 수위의 디지털 값을 얻는 영상처리 기법(Image processing)을 사용하였다. 영상처리기법을 사용하기 위하여 탱크 하단 모서리에 정사각형 모양의 파란색 표시지 2 개를 붙여 픽셀과 거리 사이의 관계를 구하였다. 또한 탱크내의 수위 변동을 용이하게 추적하기 위하여 빨간색 물감을 섞은 물 을 탱크내 액체로 사용하였다. 해상도 $1280 \times 720$, 초당 240 프레 임을 찍는 iPhone6에 내장된 카메라를 사용하였다(Hyeon and Cho, 2015). 탱크 벽에 작용하는 압력을 측정하기 위하여 초소 형 방수용 압력계(P310-02S)를 탱크 바닥으로부터 $2 \mathrm{~cm}$ 떨어진 탱크 벽면에 설치하여 압력의 시계열 자료를 취득하였다. Fig. 2 는 촬영된 동영상으로부터 탱크내 수위의 시계열 자료를 얻는 영상처리과정과 탱크 벽면에 설치된 압력계를 찍은 사진이다.

먼저 격벽이 없는 순수한 사각형 탱크의 슬로싱 실험을 실시 하였다. 탱크의 운동주기를 바꿔가면서 두 지점 $(x=-a,-0.6 a)$ 에서의 수위와 벽면 $(x=-a, z=-0.8 h)$ 에서의 압력을 측정하였
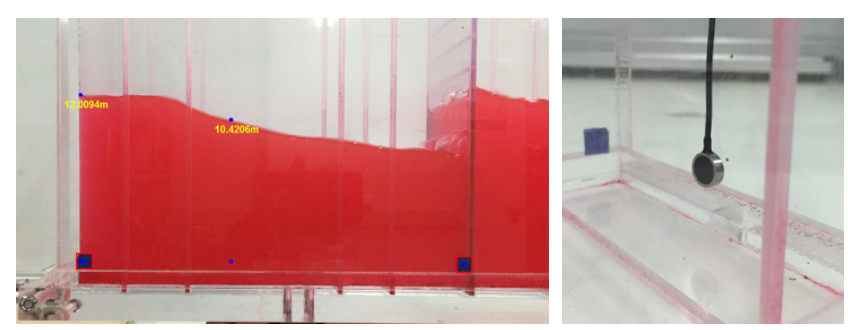

Fig. 2 Measurement of wave elevation using the image processing technique and photo of pressure gage. 
다. 다음으로 탱크 중앙에 액체의 깊이의 $1 / 2$ 만큼 잠긴 투과성 격벽을 설치하였을 때, 탱크의 운동주기와 함께 격벽의 공극률 을 바꿔가면서 동일한 실험을 반복하였다. 투과성 격벽의 위치 와 잠긴 깊이 그리고 탱크의 운동 변위는 탱크내의 유체 거동 에 영향을 주는 중요한 변수들이다. 그러나 본 실험의 목적은 2 장에서 소개한 Galerkin 방법에 기초한 설계 툴을 검증하는 것 이므로 모형실험결과의 일부분만을 해석결과와 비교하였다.

\section{4. 계산결과 및 고찰}

Galerkin 방법을 사용하여 얻은 해석해의 수렴도를 살펴보기 위하여 전개식의 개수 $(M)$ 에 따른 무차원화된 부가질량 $(\bar{\mu}=\mu / 2 \rho a h)$ 과 감쇠계수 $(\bar{\nu}=\nu / 2 \omega \rho a h)$ 의 수렴도를 2 개의 주파수 $\left(\omega^{2} h / g=0.5,1.0\right)$ 에 대하여 살펴보았다(Table 1). 전개식의 개수 $M$ 이 작다는 것은 최종적으로 풀어야 할 대수방정식의 크기가 줄어 들어 계산시간이 단축됨을 의미한다. $M(=1,2, . ., 10)$ 을 증가시키 면서 부가질량과 감쇠계수의 수렴도를 살펴본 결과, $M=5$ 이상 이면 소숫점 이하 4자리까지 일치하는 결과를 주었다. 이와 같이 Galerkin 방법이 수렴도가 좋은 이유는 격벽 끝단에서 나타나는 유속의 특이성을 전개식 (17)안에 포함시켰기 때문이다. 이후의 모든 계산에서는 정확도가 보장되는 $M=5$ 을 사용하였다.

Fig. 3은 격벽이 없는 순수한 탱크에 대한 해석결과와 모형실 험결과를 비교한 그림이다. $x$ 축은 탱크의 운동 주기이고, $y$ 축은 탱크내 두 지점 $(x=-a,-0.6 a)$ 에서 측정한 증폭비(Amplification factor)이다. 증폭비는 수위의 진폭을 탱크의 운동 진폭으로 나 눈 값 $\left(R_{a}=\left(\zeta_{\max }-\zeta_{\min }\right) / 2 \xi\right)$ 으로 정의하였다. 여기서 실선은 점 성을 무시한 순수한 포텐셜 해석결과이며, 점선은 벽과 바닥에 서의 점성 마찰에 의한 감쇠효과를 고려한 해석결과이다. 기호 (-) 는 모형실험결과이다. 본 해석해는 포텐셜 이론에 기반을 두고 있기 때문에 $\varepsilon=0$ 일 때 모델내에 어떠한 감쇠력도 존재하 지 않는다. 따라서 공진주기에서 증폭비는 무한대 값을 갖는다. 공진주기에서 해석결과와 모형실험결과가 정량적으로 잘 일치 되도록 마찰 감쇠계수를 $\varepsilon=0.4$ 로 주었다. 전반적으로 마찰 감

Table 1 Convergence test of $(\bar{\mu}, \bar{\nu})$ with truncated number $(M)$ for $a / h=4.0, d / h=0.5, P=0.1, \varepsilon=0.4$

\begin{tabular}{ccccc}
\hline \hline & $\bar{\mu}$ & $\bar{\nu}$ & $\bar{\mu}$ & $\bar{\nu}$ \\
& \multicolumn{2}{c}{$\omega^{2} h / g=0.5$} & \multicolumn{2}{c}{$\omega^{2} h / g=1.0$} \\
\hline 1 & 0.0789 & 0.1681 & -0.1077 & 0.3202 \\
2 & 0.0791 & 0.1678 & -0.1083 & 0.3208 \\
3 & 0.0791 & 0.1678 & -0.1083 & 0.3208 \\
4 & 0.0791 & 0.1678 & -0.1083 & 0.3208 \\
5 & 0.0791 & 0.1678 & -0.1083 & 0.3207 \\
6 & 0.0791 & 0.1678 & -0.1083 & 0.3207 \\
7 & 0.0791 & 0.1678 & -0.1083 & 0.3207 \\
8 & 0.0791 & 0.1678 & -0.1083 & 0.3207 \\
9 & 0.0791 & 0.1678 & -0.1083 & 0.3207 \\
10 & 0.0791 & 0.1678 & -0.1083 & 0.3207 \\
\hline
\end{tabular}

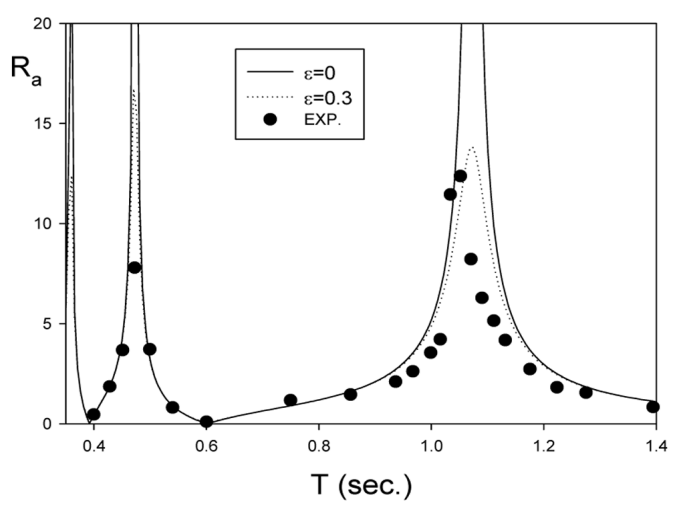

(a) $x=-a$

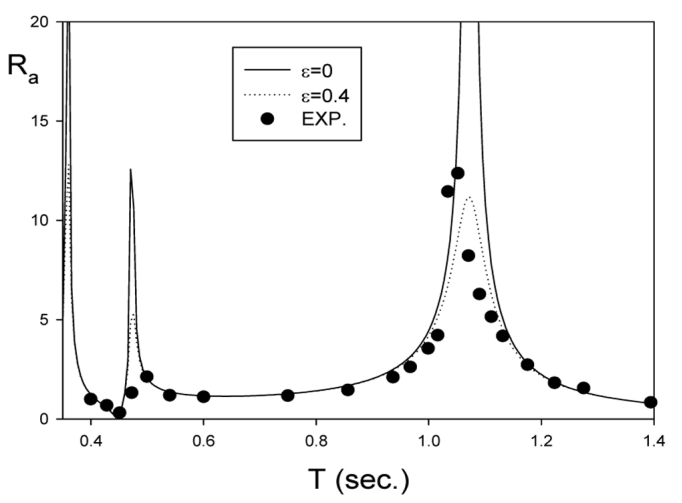

(b) $x=-0.6 a$

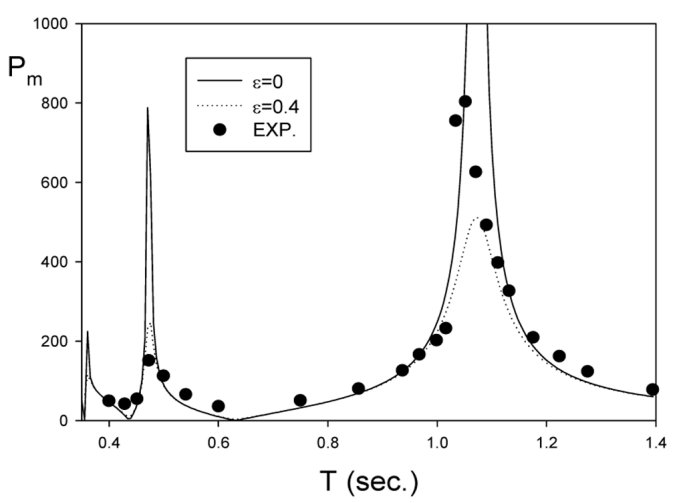

(c) $x=-a, z=-0.8 \mathrm{~h}$

Fig. 3 Comparison of the amplification factor $\left(R_{a}\right)$ and dynamic pressure $\left(P_{m}\right)$ between the analytic solutions and experimental results in a rectangular clean tank for $a / h=0.25$.

쇠계수를 주었을 때의 해석결과는 모형실험결과를 잘 따라 가 고 있음을 보여주고 있다. 이후 모든 계산에서 $\varepsilon=0.4$ 을 사용하 였다. Fig. 3 에서 탱크의 운동주기가 $0.5 \mathrm{~s}$ 와 $1.1 \mathrm{~s}$ 주변에서 증폭 비가 크게 나타나는 것은 탱크내 유체의 고유주기와 탱크의 운 동주기가 일치됨으로 발생하는 공진현상으로 설명할 수 있다. $\operatorname{Ibrahim(2005)ㄱㅏ~ㅈㅔㅅㅣㅎㅏㄴ~ㅅㅏㄱㅏㄱㅎㅕㅇ~ㅌㅐㅇㅋㅡㄴㅐㅇㅢ~ㅅㅡㄹㄹㅗㅅㅣㅇ~ㅁㅗㄷㅡ(Sloshing~}$ mode)의 고유주파수를 구하는 식은 아래와 같다.

$$
\omega_{n}=\sqrt{\frac{n \pi g}{2 a} \tanh \left(\frac{n \pi h}{2 a}\right)}, n=1,2,3, \ldots
$$


식 (27)을 이용하여 1차, 2차, 3 차 탱크내 유체의 고유주기를 계산하면 $1.07 \mathrm{~s}, 0.61 \mathrm{~s}, 0.47 \mathrm{~s}$ 이다. Fig. 3에서 1차와 3차 고유주기 에서 큰 증폭비를 보이나 2차 고유주기에서는 탱크 벽면에 Node점이 형성되어 증폭비가 작게 나타난다. 특히 공진주기가 $1.07 \mathrm{~s}$ 인 1 차 공진모드에서의 증폭비가 다른 공진모드 보다 상대 적으로 크게 나타났고 공진폭도 가장 넓었다. Fig. 3(c)는 탱크 벽면에 작용하는 압력을 서로 비교한 그림이다. $y$ 축은 탱크 바 닥에서 $2 \mathrm{~cm}$ 떨어진 탱크 벽면에서 측정한 압력의 최대값과 최 소값의 차이를 나타낸다 $\left(P_{m}=p_{\max }-p_{\min }\right)$. Fig. 3(c)에 나타난 압력 곡선은 Fig. 3(a), 3(b)의 증폭비 곡선과 비슷한 경향을 보

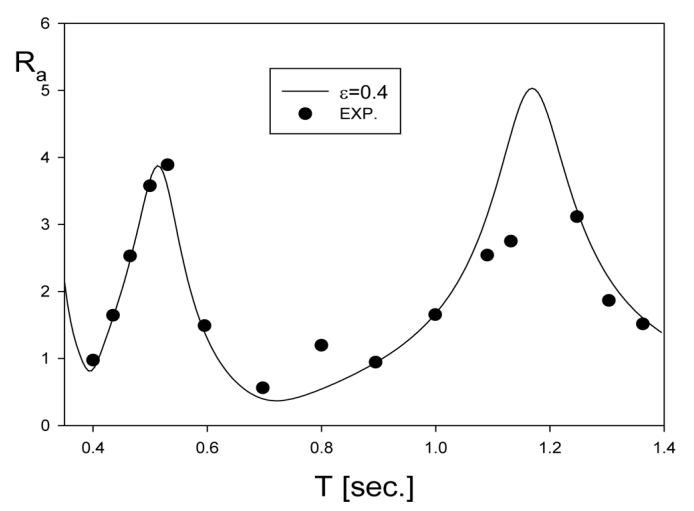

(a) $P=0.0567$

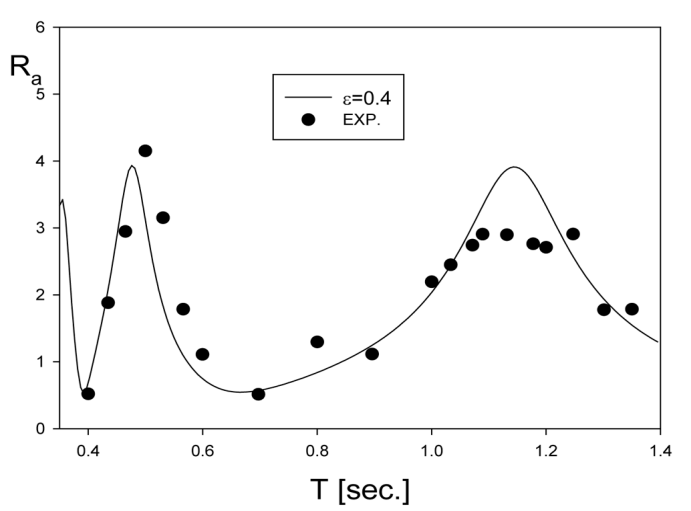

(b) $P=0.1275$

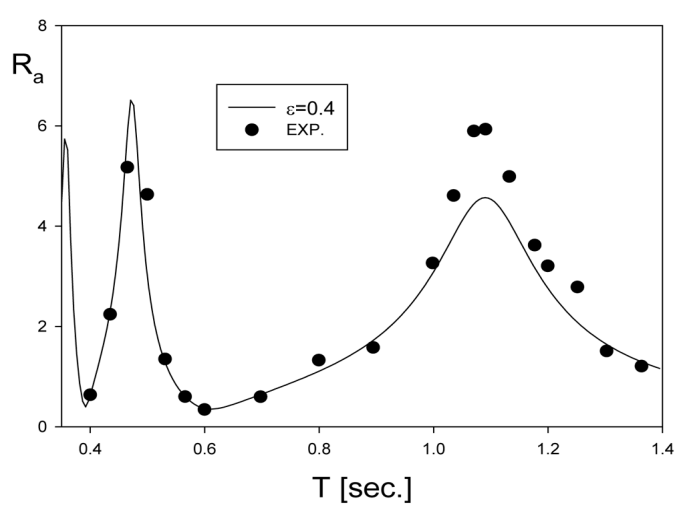

(c) $P=0.3265$

Fig. 4 Comparison of the amplification factor $\left(R_{a}\right)$ between the analytic solutions and experimental results with a porous bulkhead for $d / h=0.5, a / h=0.25$.
인다. 이는 공진으로 인해 크게 증폭된 벽면에서의 수위가 압력 값을 높이는데 크게 기여하였음을 의미한다. 비록 선형포텐셜 이론에 기반을 둔 해석해이지만 탱크의 벽과 바닥에서의 점성 마찰에 의한 감쇠계수를 고려하였을 때, 탱크내의 슬로싱 현상 을 정량적으로도 잘 구현하고 있음을 보여준다.

Fig. 4는 탱크 중앙에 공극률이 서로 다른 3장의 투과성 격벽 을 설치하였을 때의 해석결과와 모형실험결과를 비교한 그림이 다. $y$ 축은 탱크 벽면에서의 증폭비 $\left(R_{a}\right)$ 이다. 격벽의 잠긴 깊이 는 $5 \mathrm{~cm}$ 이다. 여기서 실선은 해석결과이며, 기호 $(\mathbf{O})$ 는 모형실 험결과이다. 투과성 격벽이 액체의 깊이의 $1 / 2$ 만큼 잠겨있기 때

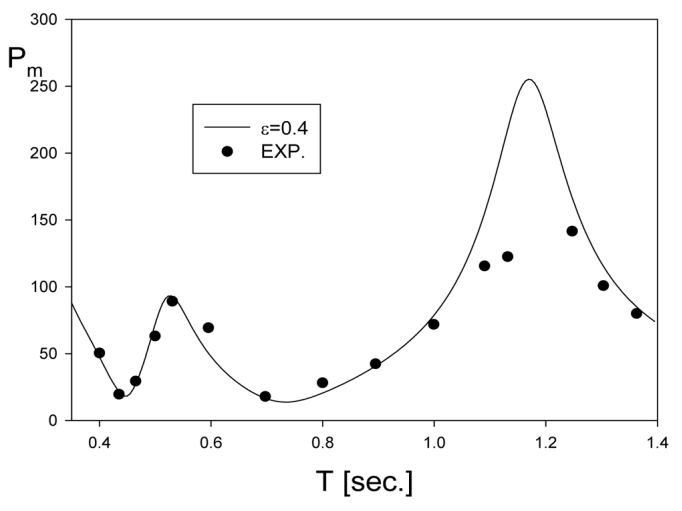

(a) $P=0.0567$

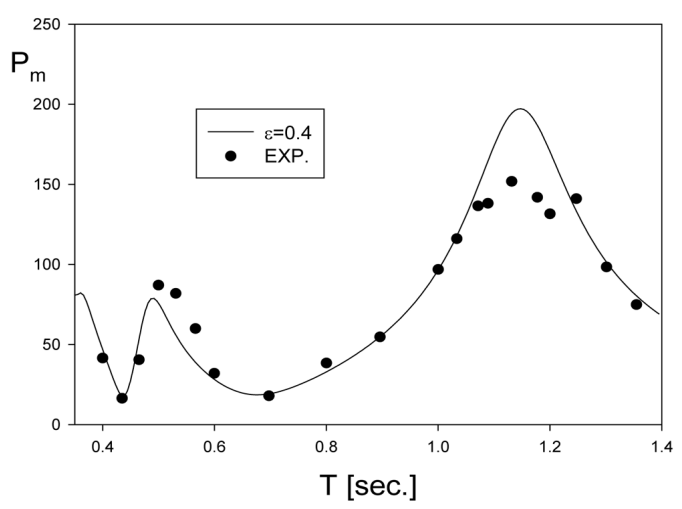

(b) $P=0.1275$

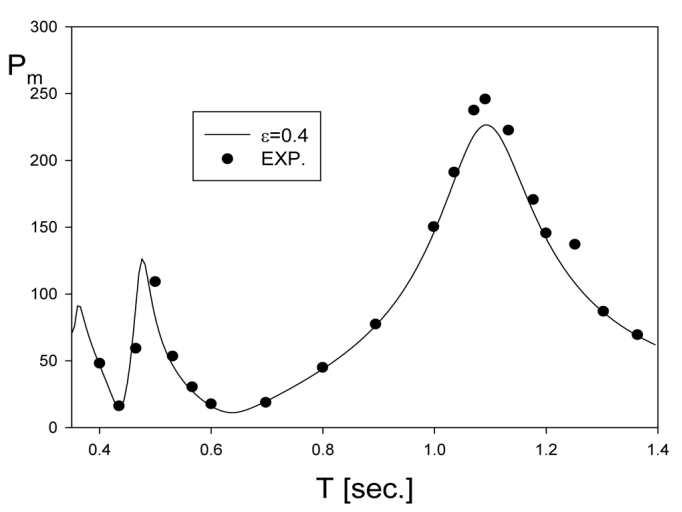

(c) $P=0.3265$

Fig. 5 Comparison of the dynamic pressure $\left(P_{m}\right)$ at tank wall between the analytic solutions and experimental results with a porous bulkhead for $d / h=0.5, a / h=0.25$. 
문에 격벽의 설치가 탱크내 수평 흐름을 제어하지 못하므로 순 수한 탱크의 공진주기와 동일한 운동주기에서 큰 증폭비를 보 이고 있다. 그러나 격벽의 설치로 인해 투과성 격벽을 통과하면 서 에너지 손실이 발생하여 격벽이 없는 순수한 탱크의 증폭비 와 비교하면 공진주기에서 증폭비가 줄어든 것을 볼 수 있다. 또한 격벽의 공극률도 증폭비에 영향을 미치는데 공극률 0.1275 인 격벽을 사용하였을 때 탱크 벽면에서의 증폭비가 가장 낮게 나타나는 것을 볼 수 있다. 즉, 공극률 0.1275 를 갖는 투과성 격 벽을 통과하면서 발생하는 에너지 손실효과가 가장 크다는 것 을 의미한다. 해석결과와 모형실험결과는 정량적으로 서로 잘 일치함을 확인하였다. 그러나 탱크의 운동 진폭을 모형실험에 서 사용한 $3 \mathrm{~mm}$ 보다 크게 하면 유체의 비선형 거동으로 해석해 와 모형실험결과는 다소 차이를 보일 것으로 예측된다.

Fig. 5는 Fig. 4와 같은 조건하에서 바닥에서 $2 \mathrm{~cm}$ 떨어진 탱크 벽면에서 측정한 압력값 $\left(P_{m}\right)$ 을 비교한 그림이다. 증폭비 곡선 과 동일하게 1 차와 3 차 공진주기에서 압력이 크게 증폭되는 것 을 알 수 있다. 또한 투과성 격벽의 설치로 인해 탱크 벽면에서 의 압력이 크게 줄어드는 것을 확인하였다. 증폭비가 가장 낮게 나오는 공극률 0.1275 인 투과성 격벽은 탱크 벽면에서의 압력을 낮추는데도 가장 효과적이다.

Fig. 6은 투과성 격벽의 잠긴 깊이 변화 $(d / h=0.2,0.4,0.6,0.8)$ 에 따른 탱크 벽면에서의 증폭비 $\left(R_{a}\right)$ 와 격벽에 작용하는 무차원화된

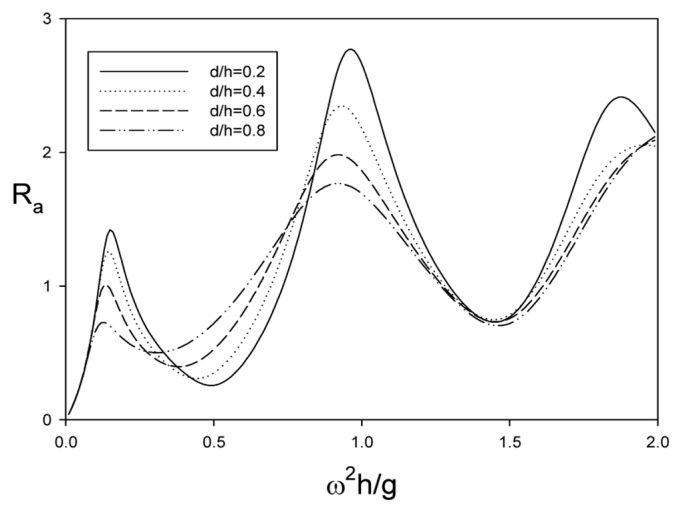

(a) Amplification factor $(x=-a)$

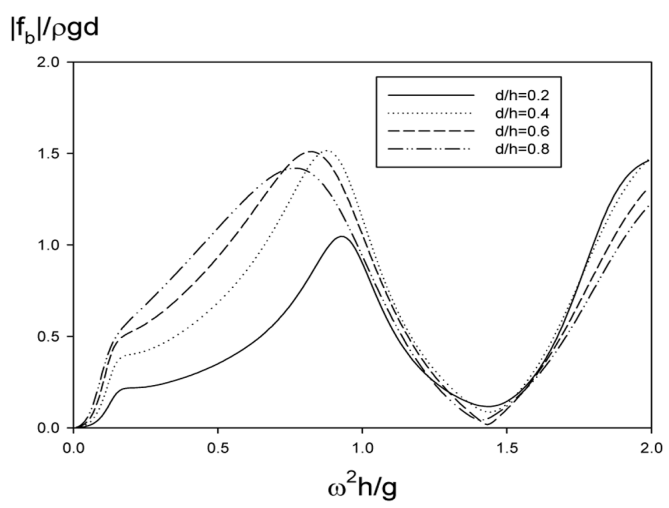

(b) Horizontal forces

Fig. 6 Amplification factor $\left(R_{a}\right)$ at tank wall and horizontal forces on a porous bulkhead as function of submergence depth $(d / h)$ for $a / h=4.0, P=0.1, \varepsilon=0.4$.
수평 하중 $\left(\left|f_{b}\right| / \rho g d\right)$ 을 그렸다. 계산조건은 $a / h=4, P=0.1, \varepsilon=0.4$ 이다. 잠긴 깊이가 가장 작은 $d / h=0.2$ 일 때 투과성 격벽을 통과하 면서 발생하는 에너지 손실이 가장 적기 때문에 공진주파수 주변 에서의 증폭비는 가장 높게 나타나며 잠긴 깊이가 증가할수록 증 폭비는 줄어드는 경향을 볼 수 있다. 격벽에 작용하는 수평 하중 은 고주파수 영역에서는 큰 차이를 보이지 않지만 저주파수 영역 에서 잠긴 깊이가 깊어질수록 증가하는 경향을 보인다. 이는 잠긴 깊이가 깊어질수록 격벽 전후의 압력차(속도포텐셜의 차이)가 커 져 결과적으로 수평 하중을 증가시켰기 때문이다.

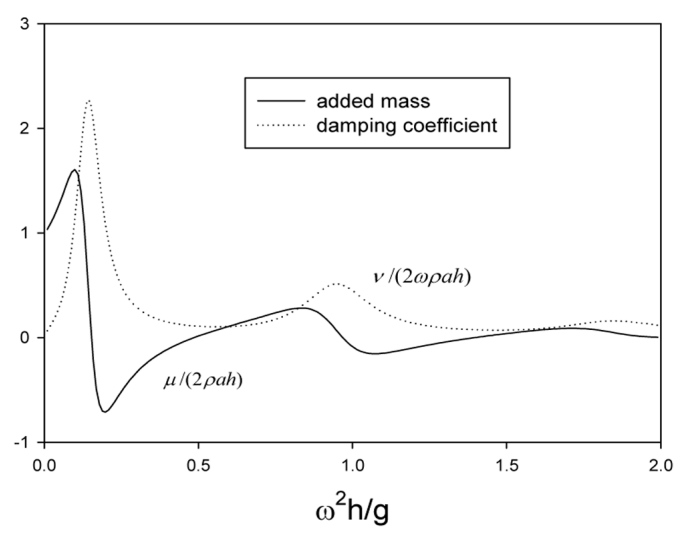

(a) $d / h=0.2$

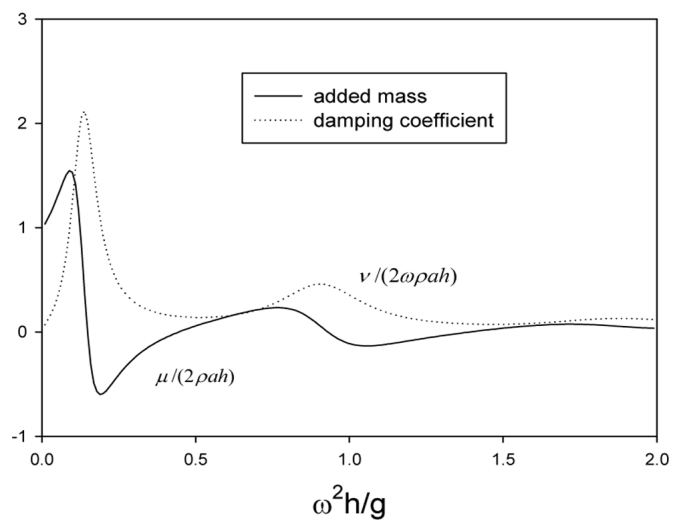

(b) $d / h=0.4$

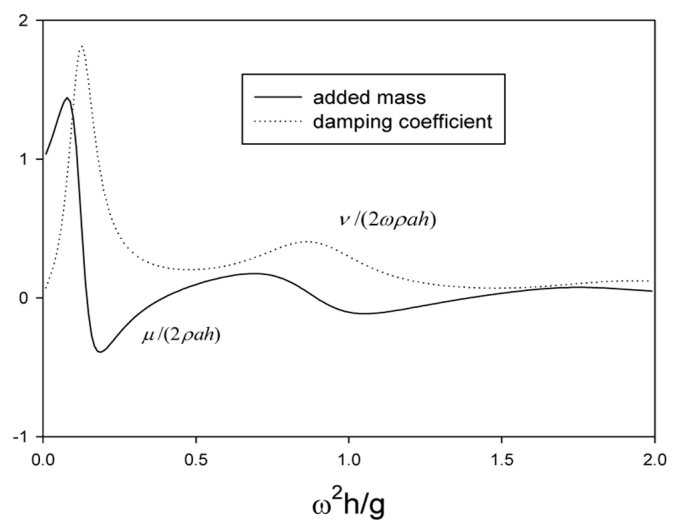

(c) $d / h=0.6$

Fig. 7 Non-dimensional added mass $(\bar{\mu})$ and damping coefficient $(\bar{\nu})$ as function of submergence depth $(d / h)$ for $a / h=4$, $P=0.1, \varepsilon=0.4$. 
Fig. 7은 격벽의 잠긴 깊이 변화에 따른 무차원화된 부가질량 $(\bar{\mu}=\mu / 2 \rho a h)$ 과 감쇠계수 $(\bar{\nu}=\nu / 2 \omega \rho a h)$ 를 보여주고 있다. 계산된 주파수 영역내에 Fig. 6(a)에서 확인하였듯이 2개의 공진주파수 $\left(\omega^{2} h / g=0.14,0.96\right)$ 가 존재하며, 공진주파수에서 부가질량은 음의 값을 갖기 시작하며 감쇠계수는 최고값을 갖는다. 이러한 독특 한 현상은 운동하는 물체 내부에 공진을 유발하는 유체영역을 가진 문제에서 주로 나타난다. 대표적인 예로는 슬로싱 문제, 문풀(Moon-pool)을 가진 해양구조물, 쌍동선, 안벽에 계류된 선 박 등이 있다. 잠긴 깊이가 증가할수록 공진주파수에서 에너지 손실효과의 증가로 부가질량과 감쇠계수가 다소 줄어드는 경향 을 보여주고 있다.

Fig. 8은 투과성 격벽의 공극률 변화 $(P=0.05,0.1,0.2,0.3)$ 에 따 른 탱크 벽면 $(x=-a)$ 에서의 증폭비와 격벽에 작용하는 무차원화 된 수평 하중을 보여주고 있다. 여기서 $a / h=4, d / h=0.5, \varepsilon=0.4$ 이 다. 탱크의 운동 주파수에 따라 차이를 보이지만 전반적으로 공극 률이 0.1 일 때 탱크 벽면에서의 증폭비가 가장 낮게 나타난다. 비록 큰 차이는 아니지만 공극률이 0.1 에 가까운 투과성 격벽을 설치하 는 것이 탱크내의 슬로싱 현상에 의해 크게 증폭된 수위를 줄이는 데 효과적임을 의미한다. 또한 격벽을 통한 에너지 손실과 관계없 이 공극률이 클수록 격벽 전후의 압력차가 줄어들어 격벽의 작용 하는 수평 하중은 줄어들었다.

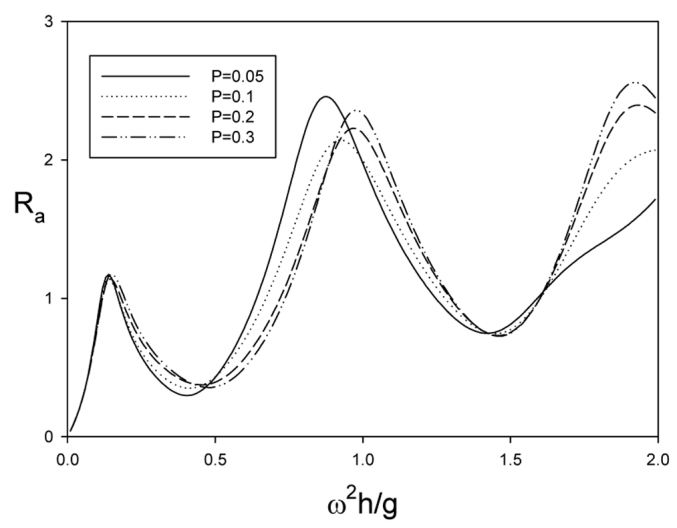

(a) amplification factor $(x=-a)$

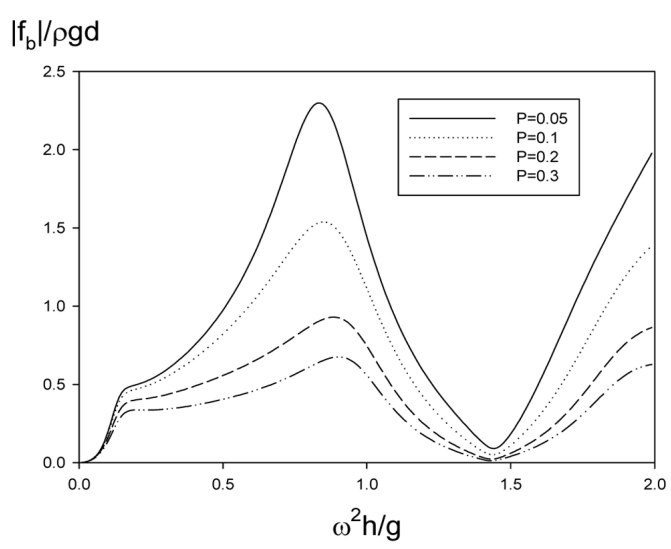

(b) horizontal forces

Fig. 8 Amplification factor $\left(R_{a}\right)$ at tank wall and horizontal forces $\left(\left|f_{b}\right| / \rho g d\right)$ on a porous bulkhead as a function of porosity for $a / h=4.0, d / h=0.5, \varepsilon=0.4$.

\section{5. 결 론}

수평 운동하는 사각형 탱크내 중앙에 투과성 격벽을 수직으 로 설치하였을 때, 탱크의 운동주기와, 격벽의 공극률, 그리고 잠긴 깊이를 바꿔가면서 탱크내의 수위 변화, 탱크 벽에 작용하 는 동유체력(부가질량, 감쇠계수), 그리고 격벽에 작용하는 수평 하중을 살펴보았다.

격벽이 없는 순수한 탱크의 슬로싱 문제에 대한 해석결과와 모형실험 결과를 비교하여 점성 마찰에 의한 감쇠계수를 $\varepsilon=0.4$ 로 하였을 때, 해석결과와 모형실험결과는 정량적으로 잘 일치 하였다. 압력 곡선은 증폭비 곡선과 비슷한 경향을 보인다. 이 는 공진으로 인해 크게 증폭된 수위가 벽면에서의 압력 $\left(P_{m}\right)$ 을 높이는데 기여하였기 때문이다.

공극률이 서로 다른 3 장의 투과성 격벽 $(P=0.0567,0.1275$, $0.3265)$ 을 탱크 중앙에 설치하였을 때, 탱크 벽면에서의 증폭비 $\left(R_{a}\right)$ 와 바닥에서 $2 \mathrm{~cm}$ 떨어진 탱크 벽면에서의 압력 $\left(P_{m}\right)$ 에 대한 해석결과와 실험결과를 비교하였다. 투과성 격벽이 액체 깊이 의 반만 잠겨 있어 격벽은 흐름을 크게 제어하지 못한다. 따라 서 순수한 탱크의 공진주기와 동일한 운동주기에서 큰 증폭비 를 보였다. 또한 투과성 격벽을 통과하면서 에너지 손실이 발생 하여 투과성 격벽의 설치로 공진주기에서의 증폭비와 압력은 줄어들었다. 특히, 공극률 0.1275 을 갖는 격벽은 증폭비와 압력 을 줄이는데 가장 효과적인 것으로 나타났다. 탱크의 벽과 바닥 에서의 점성 마찰을 고려하기 위하여 인위적으로 넣어준 마찰 감쇠계수 $(\varepsilon=0.4)$ 를 포함한 해석해는 모형실험결과를 정량적으 로 잘 따라가고 있음을 확인하였다.

격벽의 잠긴 깊이가 작을 때는 격벽을 통한 에너지 손실효과 가 작기 때문에 공진주기 주변에서 큰 증폭비를 보였다. 격벽의 잠긴 깊이가 증가할수록 공진주파수에서 증폭비는 줄어든다. 또한 잠긴 깊이가 증가는 격벽 전후의 압력차의 증가로 이어져 특히 저주파수 영역에서 수평 하중을 증가시킨다.

공극률 $P=0.1$ 에 가까운 투과성 격벽을 설치하는 것이 슬로 싱 현상으로 크게 증폭된 탱크내의 수위를 낮추는데 효과적이 다. 이는 격벽의 공극률에 따라 격벽을 통과하면서 발생하는 에 너지 손실의 차이가 생기기 때문이다.

\section{후 기}

이 논문은 2017년도 정부(교육부)의 재원으로 한국연구재단의 지원을 받아 수행된 이공분야 기초연구지원사업임(No.035231).

\section{References}

Abul-Azm, A.G., 1993. Wave Diffraction through Submerged Breakwaters. Journal of Waterway, Port, Coastal and Ocean Engineering, ASCE, 119(6), 587-605.

Cho, I.H., 2015. Sloshing Analysis in Rectangular Tank with Porous Baffle. Journal of Ocean Engineering and Technology, 29(1), 1-8.

Cho, I.H., Kim, M.H., 2016. Effect of Dual Vertical Porous Baffles 
on Sloshing Reduction in a Swaying Rectangular Tank. Ocean Engineering, 126, 364-373.

Cho, I.H., Choi, J.-S., Kim, M.H., 2017. Sloshing Reduction in a Swaying Rectangular Tank by an Horizontal Porous Baffle. Ocean Engineering, 138, 1-23.

Cho, I.H., Kim, M.H., 2008. Wave Absorbing System Using Inclined Perforated Plates. Journal of Fluid Mechanics, 608, $1-20$.

Chwang, A.T., Wu, J., 1994. Wave Scattering by Submerged Porous Disk. Journal of Waterway, Port, Coastal and Ocean Engineering, ASCE, 120, 2575-2587.

Crowley, S., Porter, R., 2012. The Effect of Slatted Screens on Waves. Journal of Engineering Mathematics, 76, 53-76.

Evans, D.V., 1970. Diffraction of Water Waves by Submerged Vertical Plate. Journal of Fluid Mechanics, 40(3), 433-451.

Faltinsen, O.M., Firoozkoohi, R., Timokha, A.N., 2011. Analytical Modeling of Liquid Sloshing in a Two-dimensional Rectangular Tank with a Slat Screen. Journal of Engineering Mathematics,
70, 93-109.

Fediw, A., Isyumov, N., Vickery, B., 1995. Performance of a Tuned Sloshing Water Damper. Journal of Wind Engineering and Industrial Aerodynamics, 57, 237-247.

Hyeon, J-W., Cho, I.H., 2015. Experimental Study on Sloshing in a Rectangular Tank with Vertical Porous Baffle. Journal of Ocean Engineering and Technology, 29(4), 291-299.

Ibrahim, R.A., 2005. Liquid Sloshing Dynamics, (Theory and Applications). Cambridge University Press.

Losada, I.J., Losada, M.A., Roldán, A.J., 1992. Propagation of Oblique Incident Waves past Rigid Vertical Thin Barriers. Applied Ocean Research, 14(3), 191-199.

Porter, R., Evans, D.V., 1995. Complementary Approximations to Wave Scattering by Vertical Barriers. Journal of Fluid Mechanics, 294, 155-180.

Warnitchai, P., Pinkaew, T., 1998. Modelling of Liquid Sloshing in Rectangular Tanks with Flow-Dampening Devices. Engineering Structure, 20, 593-600. 